Volume 10, No.3, May - June 2021

International Journal of Advanced Trends in Computer Science and Engineering

Available Online at http://www.warse.org/IJATCSE/static/pdf/file/ijatcse341032021.pdf

https://doi.org/10.30534/ijatcse/2021/341032021

\title{
Smart Learning Tools for Enhancing Basic Education System
}

\author{
Saima Siraj ${ }^{1 *}$, Ammar Oad $^{2}$, Khalida Khan ${ }^{3}$, Sajida Raz Bhutto ${ }^{5}$, Pinial Khan Butt ${ }^{4}$, Akhtar Hussain \\ Jalbani ${ }^{1}$, Rafia Naz ${ }^{1}$, Xin Liu ${ }^{2}$ \\ ${ }^{1}$ Department of Information Technology, Quaid-e-Awam University of Engineering, Science \& Technology, \\ Nawabshah,Pakistan, saimasiraj@quest.edu.pk, jalbaniakhtar@quest.edu.pk, rafia@quest.edu.pk \\ ${ }^{2}$ Faculty of Information Engineering, Shaoyang University, Shaoyang 422000, China, \\ ammar_2k309@yahoo.com, xinliu1125@163.com \\ ${ }^{3}$ Mehran University Institute of Science, Technology \& Development, Mehran University of Engineering \& \\ Technology, Jamshoro, Pakistan, kkplodhi@gmail.com \\ ${ }^{4}$ Information Technology Center, Sindh Agriculture University Tando Jam 70060, Pakistan, pinial@ sau.edu.pk \\ ${ }^{5}$ Dept of Software Engineering, MUET, SZAB Campus at Khairpur Mir's, Sindh, Pakistan, \\ sajida.raz@muetkhp.edu.pk
}

\begin{abstract}
Interactive Learning (IL) has evolved the practice of digital technology and virtual communication, mostly by students. IL can be provided by using interactive tools such as Specific, Measurable, Achievable, Realistic, and Timely (SMART) board or white boards etc. Facial expressions are receiving attention due to its recognized relevance in learning. The efficiency of interactive tools can be effectively measured from software engineering perspectives using software quality metrics that are process and product metrics. In this paper, product quality metrics from customers perspective was used as the interactive tools has assessed by the users. The aim of this paper is to realize the impact of interactive tools in primary education and to measure the effectiveness of interactive tools through facial expressions of students. We found this study very successful as only $15 \%$ of students had negative response of using interactive tools in the form of angry, sad and disgust however $85 \%$ of students had positive response that they had enjoyed in the form of happy, surprise and neutral in primary education level and in secondary education level there is a $15 \%$ improvement has been found in the results. It was concluded from this study that most of the students were satisfied with the interactive tools and their academic performance was highly improved as compared to traditional system of learning.
\end{abstract}

Key words: Interactive Learning, Facial Expressions, Software Quality Product Metrics, Interactive Tools.

\section{INTRODUCTION}

The use of new technologies and techniques in educational system has given remarkable results in student's learning process [1]. The introduction of advanced techniques and tools in learning system has opened new discussion and research work in this field thus can be called as Revival of Learning system. The distributions of learning, training or education platform using electronic media become the more widespread among the new world. The use of IL has made learning and acquiring knowledge easy, attractive and interested. In recent years there has been an emergent interest in educating all aspects of the interaction between human and computer, by using IL techniques the traditional method of work switched to digital designed applications. By using IL techniques and tools, facial expression and emotion plays very important role in determining the achievements of students in learning process. The IL in combination with digital technologies, facial expression and emotion becomes IL methodology and brings fruitful results in our education system. In different studies it is highlighted, when students use IL techniques and robotic tools, they show keen interest in learning and for them it is also a fun [2]. The advent of technology in educational institutions had brought remarkable changes in the educational system in developing countries, as the introduction of the Smart Board (SB) is being appreciated and highlighted [3].

The introduction and adoption of the smart ways of learning in all subjects is necessary. As life becomes more virtual with the usage of new modern techniques and tools for effective learning subjects. The science is further classified in different fields and subjects. By the incorporated smart learning tools has developed interest in classroom [4]. Major problem to analyze the human behavior in term of facial expressions especially in primary level students. Käser et. al. [5] faces difficulty in the collection of experimental data in quality and quantity wise. The tools which are used for IL should be according to software quality metrics, to measure the effectiveness of interactive tools the product should be evaluated and analyzed according to customer-oriented metrics [6-9]. The purpose of this study was to examine the efficiency of interactive tools in primary and secondary education level. 
This paper begins by considering the efficiency of IL tools in section II there is a background and section III discusses the methodology of this research section IV have the details of data collection on primary education level. Section V shows the results of primary level. Section VI shows the secondary level data use in this study and VII shows the data collection. Section VIII explains the results of secondary level and in section IX draws conclusion and Section X future work.

\section{BACKGROUND STUDIES}

The Artificial Intelligence (AI) is the art of engineering for making intelligent machines and science of advance computer programs that perform tasks automatically with help of human intelligence for problem solving, games and other discoveries [10]. Currently Human-Computer Interaction (HCI) is emerging and wide spread field and researchers are trying to explore simple and easier in use by involving the natural communication and operate thought of human skillfully. According to the research facial expression has great importance in communication speeches, major share of communication speeches is of facial expression, hence in $\mathrm{HCI}$ facial expression has major role for producing such computer which understand and recognize facial expression [11-12]. Sabry and Barker [13] shows influence of HCI over IL systems in accordance to Information Technologies (IT), techniques, design, laws and principle. The learning is a process of acquiring knowledge that may be new, modified and existing knowledge. Learning is a natural act of information, education, personal experiences and schools [14]. IL is governing force to boost its ability to learn effectively and efficiently [15]. The student's shows keenness in communicating with interactive techniques as they play games and virtual oriented systems thus emerges powerful medium for affective learning [16-17]. Computer oriented tools are the most famous way of engaging students and develops the positive and constructive abilities with different ways, the learners are motivated to prepare and produce their own way of learning environment [18]. It is figured out that elements that influence Information and Communications Technology (ICT) integration in the field of education are reciprocal to each other as shown in Figure1. The ICT integration should be summed as whole with consultation of all stakeholders [19].

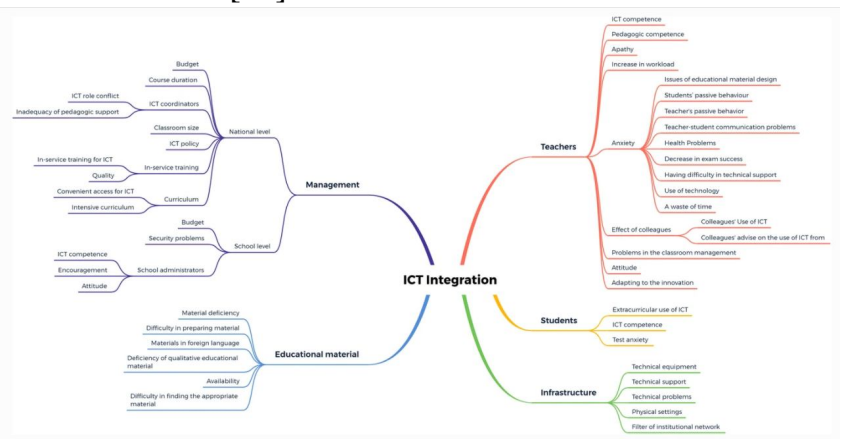

Figure 1: ICT Integration [17]
The human behavior with respect to the facial expressions and emotions specially has great ability to perceive the level of understanding of learning and from facial expression we can judge the level of engagement towards learning of student. The students communicating with modern technology -based techniques are enjoying the classroom and their level of engagement is comparatively more than traditional method of learning and they are more motivated to take part in the class [20-21]. In human life emotions reflect a level of interest in all age groups especially in the educational field, irrespective of the culture, race, and language. The emotions are taken as a universal mode of understanding [22]. According to different studies, the student's behavior and facial expression are very much important in calculating and analyzing level of understanding the lesson while using interactive techniques [23]. The product metrics explain the aspects of product such as size, complication, design parameters, achievements and level of quality. Two problems related to product quantity metrics i.e., customer problem and customer satisfaction perspective. The problems usually customer face while using the software product, problem may be performance and usability. The customer satisfaction is generally measured by marketing and customer survey methods [1].

\section{METHODOLOGY}

This study is divided into two parts. The first one focuses on the primary education and second for the secondary education.

The methodology followed for primary education in this research is discussed in Figure 2.

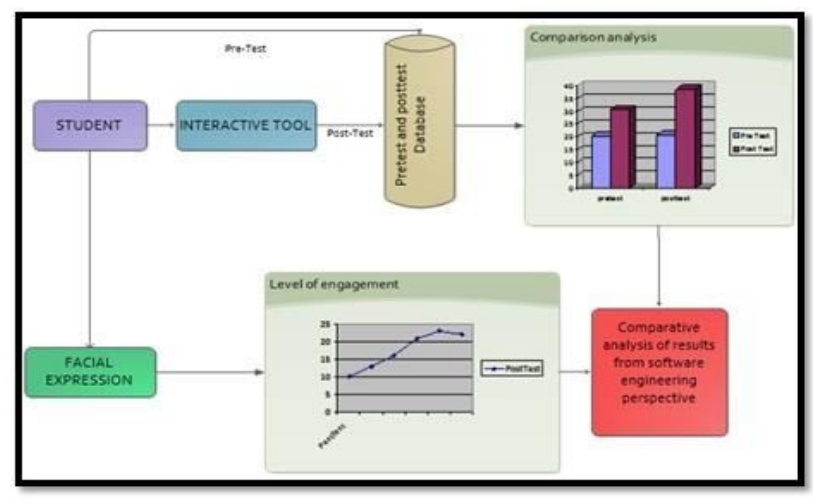

Figure 2: Methodology

In this paper the multiple experiments were performed in which students are the subject for those experiments. We have selected the students of the Smart School, Nawabshah, Pakistan, for performing the experiment. For the experiment two Tools were used and they are Flexi-Master and SB Applications.

This study will measure the facial expression of students by using these tools. In pretest we get academic record from school when students are not using any interactive tool and in posttest results after experiencing the use of interactive tools. We have collected the videos of student during interaction 
with the software tools and used these videos frames as an input to Face Reader to acquire the facial expressions. Finally, the software quality metric applied to provide comparative analysis of results.

\section{DATA COLLECTION}

To conduct this study; nearly two months were consumed in the collection of the data. We have arranged the group of 10 students and took the facial expressions of every group for 20-25 minutes.

The profile of research participants is presented in Table1.

Table 1: Male and Female Students

\begin{tabular}{|c|c|c|c|}
\hline No. & Class Level & $\begin{array}{c}\text { Number of } \\
\text { Male Students }\end{array}$ & $\begin{array}{c}\text { Number of } \\
\text { Female } \\
\text { Students }\end{array}$ \\
\hline 1. & Play Group & 13 & 17 \\
\hline 2. & Class Nursery & 20 & 18 \\
\hline 3. & Class kindergarten & 15 & 20 \\
\hline 4. & Class One & 09 & 08 \\
\hline
\end{tabular}

Participants were primary school students. The course was a Basic English and Mathematics course and the syllabus include general knowledge and Rhymes. We use the recorded video sequence to extract the Facial Expressions. We obtain data from 120 students. The student's expressions measured by the Face Reader.

\section{RESULTS FOR PRIMARY LEVEL}

This section presents the results of primary level's Figure 3 showed that when the SB Application was used by the nursery class student, found it very interesting and $99.1 \%$ of the expressions are shown in happy mood. In the circumflex model of effect, it is clearly depicted that student is in active and pleasant state. Student enjoys learning using SB Application.

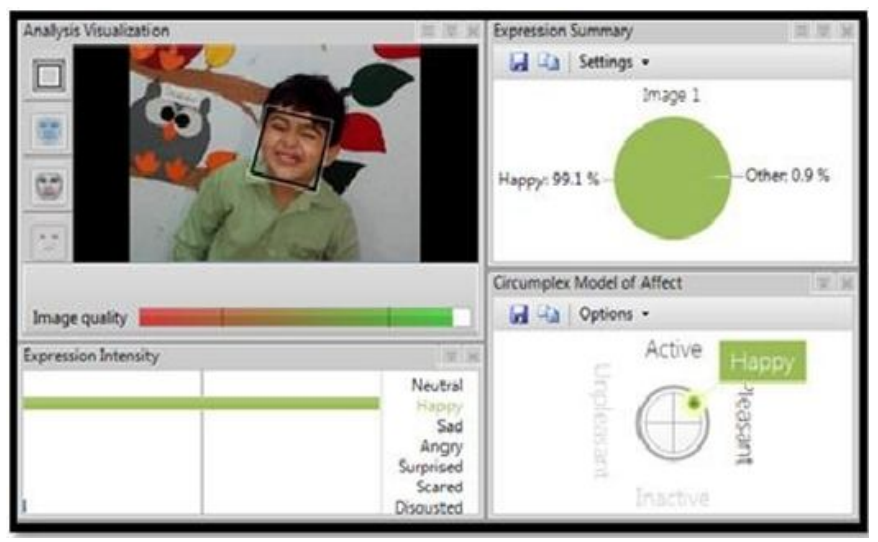

Figure 3: Interaction with Interactive Board

The data in Figure 4 shows the response of the student when the Flexi-Master application was used by nursery class student and found it very interesting and $78.6 \%$ of the expression are shown in happy mood, $19.9 \%$ were neutral while $1.5 \%$ of the emotions are for the rest of the emotions like sad and angry. This study showed that with the usage of Flexi-Master the level of student learning has increased.

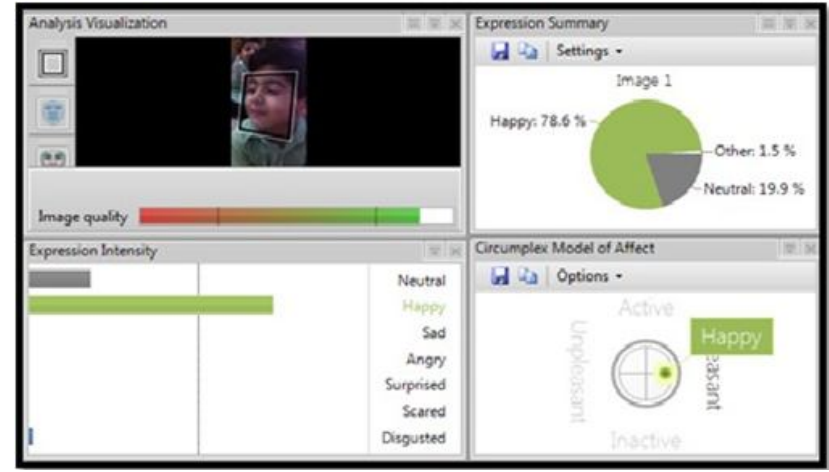

Figure 4: Interaction with Flexi Master

\subsection{Customer Problem and Customer Satisfaction}

Figure 5 shows the results of the students according to software engineering perspectives; students are satisfied from these interactive tools. A very few students show their negative response in the form of scared and disgusted as they feel problem in communicating and operating with interactive tools. On $\mathrm{x}$ axis there are features which are used in this study to measure the satisfaction of the students and Yaxis shows the percentage of these features.

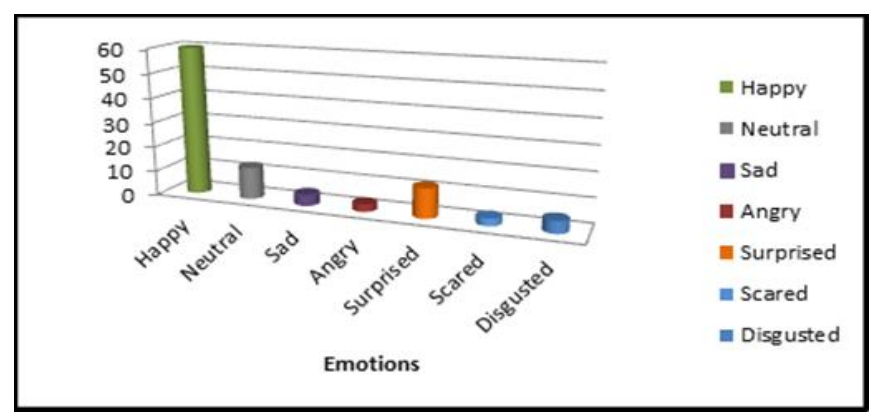

Figure 5: Customer Satisfaction Results

\subsection{Performance of Selected Tools}

In this section we have discussed the performance of tools which were selected in primary level in this research. The tools used in this research had shown very promising results. Figure 6 shows that when students were on manual learning system there learning were average and when the same students used the interactive tools there is a dramatic increase in their level of learning.

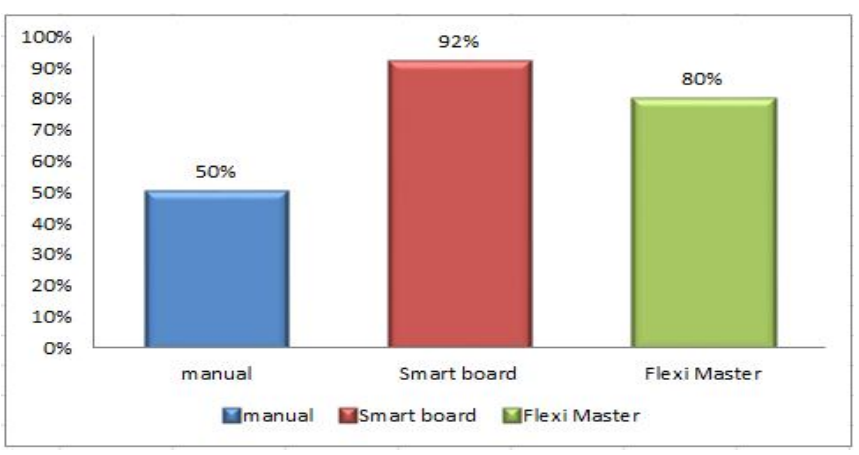

Figure 6: Performance of Selected Tools 


\section{SECONDARY EDUCATION LEVEL}

In the second step of methodology the secondary education level has been focused. The data has been collected from The Bakhtawar Cadet College for Girls, Shaheed Benazirabad, Pakistan, for secondary level education.

\section{DATA COLLECTION}

The data of 169 students has been collected from examination department. The collected data have both results before and after implementing interactive tool as shown in Table 2

Table 2: Students for Secondary Education Level

\begin{tabular}{|c|c|}
\hline Class Level & Number of Students \\
\hline $8^{\text {th }}$ & 58 \\
\hline $9^{\text {th }}$ & 57 \\
\hline $10^{\text {th }}$ & 54 \\
\hline
\end{tabular}

The data in Figure 7 shows the interaction of students with smart board

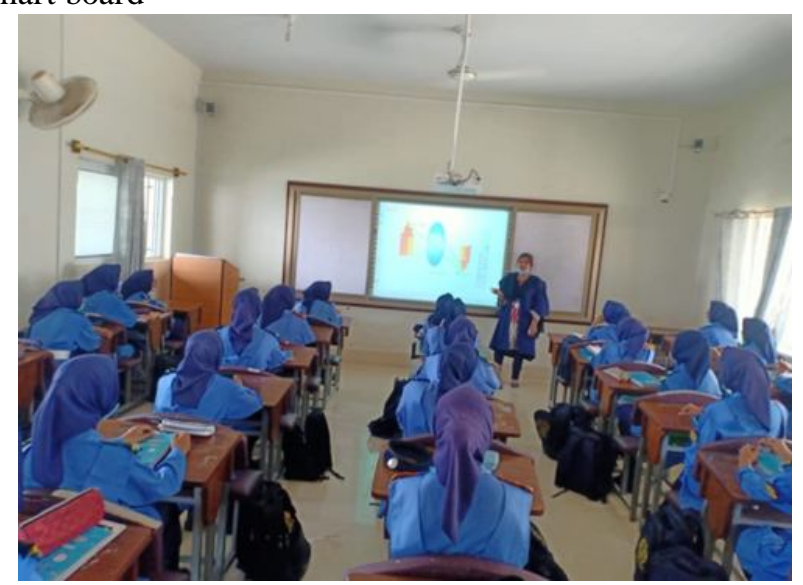

Figure 7: Interaction with Smart Board

\section{RESULTS OF SECONDRY LEVEL}

To conclude the results of the secondary level of education the descriptive statistical analysis has been performed on the data. Table 3 shows the average \% of each class with and without interactive smart tool.

Table 3: Average Percentages of Secondary Education Level

\begin{tabular}{|c|c|c|}
\hline $\begin{array}{c}\text { Clas } \\
\mathbf{S}\end{array}$ & $\begin{array}{c}\text { Before Interactive Tools } \\
(\boldsymbol{\%})\end{array}$ & $\begin{array}{c}\text { After Interactive tools } \\
(\boldsymbol{\%})\end{array}$ \\
\hline $8^{\text {th }}$ & 78.60 & 83.85 \\
\hline $9^{\text {th }}$ & 75.01 & 80.28 \\
\hline $10^{\text {th }}$ & 70.58 & 80.06 \\
\hline
\end{tabular}

The data in Table 4 shows the randomly selected students elaborates their learning outcome with support of technological interactive tools of each class at secondary level.
Table 4. Randomly Selected Results

\begin{tabular}{|c|c|c|c|}
\hline No. & $\begin{array}{c}\text { Clas } \\
\mathbf{s}\end{array}$ & $\begin{array}{c}\text { Results Before Using } \\
\text { Technology Tools } \\
(\%)\end{array}$ & $\begin{array}{c}\text { Results After Using } \\
\text { Technology Tools } \\
(\%)\end{array}$ \\
\hline 1. & \multirow{10}{*}{$8^{\text {th }}$} & 48.67 & 67.71 \\
\hline 2. & & 38.86 & 49.43 \\
\hline 3. & & 74.95 & 73.14 \\
\hline 4. & & 60.00 & 68.00 \\
\hline 5. & & 58.76 & 73.00 \\
\hline 6. & & 57.86 & 69.00 \\
\hline 7. & & 95.81 & 91.00 \\
\hline 8. & & 82.00 & 80.00 \\
\hline 9. & & 72.00 & 79.43 \\
\hline 10. & & 49.24 & 57.71 \\
\hline 11. & \multirow{9}{*}{$9^{\text {th }}$} & 77.10 & 85.33 \\
\hline 12. & & 59.71 & 75.33 \\
\hline 13. & & 69.81 & 82.67 \\
\hline 14. & & 70.86 & 82.00 \\
\hline 15. & & 61.05 & 82.00 \\
\hline 16. & & 73.90 & 85.00 \\
\hline 17. & & 69.48 & 62.33 \\
\hline 18. & & 81.10 & 84.33 \\
\hline 19. & & 92.43 & 92.33 \\
\hline 20. & \multirow{7}{*}{$10^{\text {th }}$} & 79.50 & 93.75 \\
\hline 21. & & 87.47 & 89.25 \\
\hline 22. & & 88.33 & 74.50 \\
\hline 23. & & 80.03 & 72.00 \\
\hline 24. & & 67.00 & 67.00 \\
\hline 25. & & 75.03 & 88.00 \\
\hline 26. & & 71.06 & 75.75 \\
\hline
\end{tabular}




\subsection{Descriptive Statistical Analysis}

Table 5 shows the results of the statistical analysis has performed on the data and gets improved results after implementing interactive tools in secondary education level.

Table 5: Statistical Analysis

\begin{tabular}{|c|c|c|c|}
\hline Variable & Count & Mean & $\begin{array}{c}\text { Standard } \\
\text { Deviation }\end{array}$ \\
\hline Without Tool & \multirow{2}{*}{169} & 75.1462 & 12.2154 \\
\cline { 1 - 1 } \cline { 3 - 4 } With Tool & & 81.4356 & 9.48016 \\
\hline
\end{tabular}

\section{CONCLUSION}

After analyzing the pretest and posttest results, we come to know that when students were on the manual system their percentage is 50, when they are using the SB application their level of learning is increasing near to touch the limit of $80 \%$ and when they are communicating with the flexi-master they show positive result in increasing the learning percentage up to $80 \%$ of the student. On the whole SB perform well in comparison to flexi-master results showed that only $15 \%$ of students had negative response in form of angry, sad and disgust however $85 \%$ of students had positive response that they had enjoyed in the form of happy, neutral and surprise. In this study, we have measured students' learning using two interactive tools that are SB application and flexi-master and comparatively analyzed the results based on software quality metrics that are customer satisfaction and customer problem. From these results, it can be concluded that most of the students are satisfied with the tools. There were some problems found during the research study which need to be considered before implementing the tools in the schools. Now-a-day's IL and interactive tools are well known in education system and with the involvement of these interactive tools remarkable results in student learning has achieved. In this research the attention of students is measured when they were communicating with interactive tools in the form of facial expressions for the primary education level. In the secondary education system measured the performance with the help of exam results and calculated the mean of 81.43 after implementing the interactive tools technology.

\section{FUTUREWORK}

As a future work, following updates will be implemented in this work:

- This research study can be extended to involve more students of other classes in the future.

- In future other interactive software tools can be used to analyze the better one used in schools.
- In future more factors of software engineering can also be involved to analyze the software. The limitation of this research study is that the children of fewer than seven-year-old are focused.

\section{ACKNOWLEDGEMENT}

The acknowledgement would remain incomplete without thanking to Dr. Brig (Rtd.) Muhammad Amin, Principal, and Umme Rubab, Bakhtawar Cadet College for Girls, Shaheed Benzairabad, Pakistan, for providing data for Secondary level learning's and Mrs. Urooj Zahid, The Smart School Nawabshah, Pakistan, for primary level data. Authors are also thankful to the Shaoyang University, Shaoyang China and Quaid-e-Awam University of Engineering Science \& Technology, Nawabshah, Pakistan.

\section{REFERENCES}

1. Simoni, M., "Using Tablet PCs and Interactive Software in IC Design Courses to Improve Learning",

Journal of IEEE Transactions on Education, Volume 54, No. 2, pp. 216-221, 2011.

2. Fridin, M., "Storytelling by a Kindergarten Social Assistive Robot: A Tool for Constructive Learning in Preschool Education", Computers \& Education, Volume 70, pp. 53-64, 2014.

3. Mesut, G.Ü.N., and Yilmaz, A., "Perceptions of Secondary School 8th Grade Students Regarding Smart Board Concept", Dilve Dilbilimi Çalışmaları Dergisi, Volume 16, No. 1, pp. 154-165, 2020.

4. Iqbal, F., "Role of Smart Classes on Science Teaching Towards Attitude and Achievement of Secondary School Students", Jamshedpur Research Review, 2020.

5. Käser, T., Baschera, G.-M., Busetto, A.G., Klingler, S., Solenthaler, B., Buhmann, J.M., and Gross, M., "Towards a Framework for Modelling Engagement Dynamics in Multiple Learning Domains", International Journal of Artificial Intelligence in Education, Volume 18, 2013.

6. Kan, S.H., "Metrics and Models in Software Quality Engineering", Addison-Wesley Longman Publishing Co. Inc., 2002.

7. Hauser, J.R., and Katz, G.M., "Metrics: You are What You Measure!", European Management Journal, Volume 16, No. 5, pp. 517-528, 1998.

8. Brown, M.G., "Keeping Score: Using the Right Metrics to Drive World-Class Performance", Productivity Press Inc., 1996.

9. Jones, T.O., and Sesser, W.E., "Why Satisfied Customers Defect", Harvard Business Review Volume 73, No. 6, pp. 88, 1995.

10. Fethi, M.D., and Pasiouras, F., "Assessing Bank Efficiency and Performance with Operational Research and Artificial Intelligence Techniques: A Survey", European Journal of Operational Research, Volume 204, No. 2, pp. 189-198, 2010. 
11. Bashyal, S., and Venayagamoorthy, G.K., "Recognition of Facial Expressions Using Gabor Wavelets and Learning Vector Quantization", Engineering Applications of Artificial Intelligence, Volume 21, No. 7, pp. 1056-1064, 2008.

12. Ren, Z., Meng, J., and Yuan, J., "Depth Camera Based Hand Gesture Recognition and Its Applications in Human-Computer-Interaction", IEEE $8^{\text {th }}$ International Conference on Information, Communications and Signal Processing, 2011.

13. Sabry, K., and Barker, J., "Dynamic Interactive Learning Systems", Innovations in Education and Teaching International, Volume 46, No. 2, pp. 185-197, 2009.

14. Chance, P., "Learning and Behavior", Cengage Learning, $7^{\text {th }}$ Edition, 2013.

15. Balan, P., and Kalavally, V., "Enhancing Student Motivation in Process Control via Interactive Learning Tools", IEEE $4^{\text {th }}$ International Conference on Technology for Education (T4E), 2012.

16. Weller, A.V., "The Use of Web 2.0 Technology for Pre-Service Teacher Learning in Science Education", Research Teacher Education, Volume 3, No. 2, pp. 40-46, October, 2013.

17. Zarwina, Y., Katmon, S.A., Ahmad, M.N., and Miswan, S.H.M., "Visual Representation: Enhancing Students' Learning Engagement through Knowledge Visualization", IEEE International Conference on Informatics and Creative Multimedia (ICICM), 2013.

18. Tizard, B., and Martin, H., "Young Children Learning", John Wiley \& Sons, 2008.

19. Urgut, Y.E., and Aslan, A., "Factors Affecting ICT Integration in Turkish Education: A Systematic Review", Education and Information Technologies, pp, 1-24, 2021.

20. Dharmawansa, A.D., Katsuko T.N., and Yoshimi, F., "Develop a Monitoring Tool and Extract Facial Expression towards the Analyzing Student Behavior in Three-Dimensional Virtual Environment”, IEEE International Conference on Biometrics and Kansei Engineering (ICBAKE), 2011.

21. Grafsgaard, J.F., Wiggins, J.B., Boyer, K.E., Wiebe, E.N., and Laster, J.C., "Automatically Recognizing Facial Expression: Predicting Engagement and Frustration", Proceedings of $6^{\text {th }}$ International Conference on Educational Data Mining, 2013.

22. Tonguç, G., and Ozkara, B.O., "Automatic Recognition of Student Emotions from Facial Expressions during a Lecture", Computers \& Education, Volume 148,103797, 2020.

23. Sandbach, G., Zafeiriou, S., Pantic, M., and Yin, L., "Static and Dynamic 3D Facial Expression Recognition: A Comprehensive Survey", Image and Vision Computing, Volume 30, No. 10, pp. 683-697, 2012. 